\title{
AN ASSESSMENT OF EDIBLE COATING AND ITS IMPACT ON SHELF LIFE AND POST HARVEST QUALITY OF GUAVA (PSIDIUM GUAJAVA L.) FRUITS - A REVIEW
}

\author{
Shaifali \\ School of Agriculture, Lovely Professional University, Punjab
}

Received: 15.09.2020

Revised: 28.09.2020

Accepted: 07.10.2020

\begin{abstract}
Legitimate postharvest treatment of food produces is a higher priority than the serious and broad cultivating in making sure about nourishment for a country, since misfortunes are a misuse of food as well as they speak to a comparable misuse of human exertion, ranch inputs, jobs, speculations and scant recourses, for example, water. Postharvest misfortunes of agricultural yields when all is said in done and new products of the soil (perishables) specifically are normal issues in creating nations, similar to Ethiopia, which negatively affects the food security program. This is mostly a direct result of their transitory nature, absence of information and deficiency of capital. The other explanation is that a large portion of these perishables are delivered by little scope ranchers the individuals who have restricted information and monetarily poor in the creating nations. Along these lines, assessment of postharvest misfortunes of new foods grown from the ground is exceptionally significant for mindfulness creation to deal with the produce appropriately in order to spare from waste and harms by physical and physiological methods. The destinations of this audit are, hence, to evaluate the accessible writings on the postharvest misfortunes of new foods grown from the ground trying to distinguish need zones of the issue; to distinguish the reasons for misfortunes of perishables so as to dodge the foundations for the decrease of misfortunes; and to distinguish the potential methodologies that can decrease misfortunes and keep up nature of the items during the period.
\end{abstract}

Keywords: Shelf life, Postharvest losses, Coatings, Waxing.

\section{INTRODUCTION}

Purchasers around the globe interest for food of highcaliber, without concoction additives, and an all-inclusive time span of usability (Jawadul et al. 2014). Postharvest misfortunes of tropical organic products are a major issue in view of quick decay during taking care of, transport and capacity (Adentuji C.O et al. 2012). Endeavors ought to be made to incorporate creation with postharvest the board since postharvest misfortune decrease has extensive bearing on food accessibility. Protection of organic products under encompassing conditions is important to expand their time span of usability and to improve commercialization (Krishna K. and Rao, 2014). These are responsible for its rich genetic diversity in fruit crops, resulting in good amount of divergence at different centers in respect to perennial fruit crops viz., mango, citrus, grapes, guava, banana, aonla, bael, litchi, jamun, several underutilized and temperate fruits for crop improvement (Tomar et al., 2020).

Guava is one of the most tasty and nutritious natural products, loved by the purchasers for its reviving taste and wonderful flavor (Adentuji C.O et al. 2012). Because of its climacteric nature the organic product ages quickly and subsequently exceptionally transitory, with a short timeframe of realistic usability extending from 2-3 days at room temperature. Retailing of guava natural products in India is normally done under non - refrigerated conditions. Therefore, palatable coatings dependent on normal items can

*Corresponding author: shifnanda@gmail.com 
give an extra assurance to new leafy foods. Eatable covering is a straightforward film that covers the food thing and goes about as a hindrance to stickiness and oxygen. There are a few sorts of eatable coatings, for example, sugar, protein, lipid and a blend of every one of these materials. (Wijewardane R.M.N.A 2013). Aloevera acceptable coatings which are gel-based, they have been seemed to hinder reduction of moistness and strength, improvement headway, control respiratory rate and lessen microorganism extension in natural items, for instance, table grapes, sweet organic products, and so on (Juan et al. 2005).

Xanthan gum is a polysaccharide gum which has an assortment of use in the food business as a settling, viscosifying, emulsifying, thickening and suspend operator (Aniseh and Shabanpour 2013). Thickener has been found to broaden the timeframe of realistic usability of negligibly prepared prickle pear upto 9 days (Asrar Y.I et al. 2013). Gum arabic, acquired from stems or parts of Acacia species, is the most regular polysaccharide utilized. It is an emulsifier and has film framing and epitome properties. It was discovered that gum arabic upgraded timeframe of realistic usability as well as kept up postharvest nature of develop green tomatoes for as long as 20 days during capacity at 20॰C. Different strategies have additionally been assessed for use of various sorts of covering materials. They are generally straightforwardly applied on the food surface by plunging, splashing or brushing. Stearin based wax covering applied by hand cleaning procedure could successfully improve the quality and time span of usability of guava (Abraham and Banarjee, 2018).

The current examination identifies with discover the pertinence of another eatable covering detailing comprising of Aloe-vera gel and thickener in upgrading the timeframe of realistic usability and nature of guava (Abraham and Banarjee, 2018). The novelty and appearance at the hour of obtainment choose the idea of new cut natural products (Kader, 2002). Negligible treatment of new cut normal items, which incorporates assessing, washing, orchestrating, stripping, cutting and packaging, can impact the decency of the nourishments developed from the beginning gets changed and waste of microbial that may bring about decay of the concealing, surface along with sort of natural items (Watada and Qi, 1999). The ejection of the trademark defence layer of common items does spillage of juices what's more, sugar amount out of the hurt mass coming to fruition within the natural items being significantly powerless to disease causing agent (Oms-Oliu et al. 2010).

Through an assessment, information could be accumulated about the effect of included substances, for instance, malignant growth avoidance operators, surface strengthener along with expert of antimicrobial in Aloe vera gel as an agreeable covering for fresh sliced guava (Nasution et al. 2015). Moreover, this assessment would incorporate to the grouping of wellsprings of consumable coatings. The normal wellsprings of consumable coatings used for freshcut characteristic items, for instance, starch, chitosan, carrageenan, casein and whey protein are not as successfully open as Aloe vera plants are. Starting at now, Aloe vera gel is usually used in the making of tablets, beverages, balms, chemical and also along with cleaning agent. As such, the very feasable usage of Aloe vera gel as a consumable concealing can change its utilization (RojasGrau et al. 2009a)

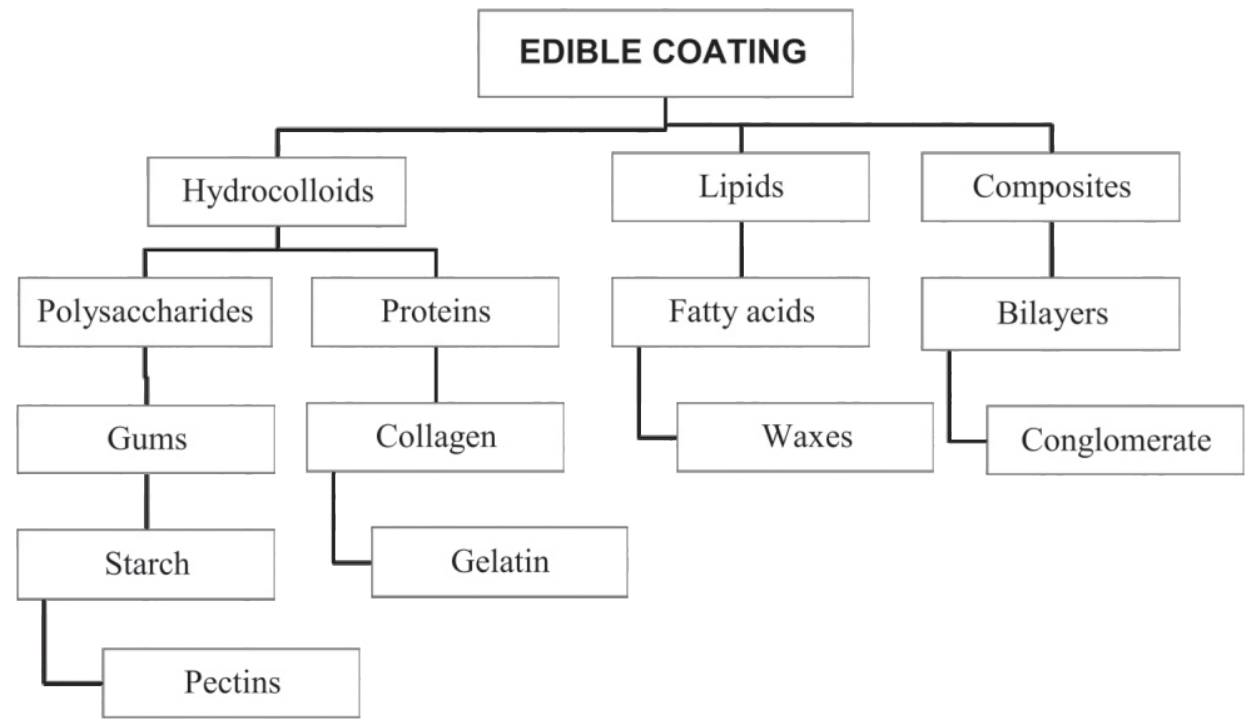

Chart: Various types of Edible Coatings (Raghav et al. 2016) 


\begin{abstract}
Aloevera: A Noble Coating
New mechanical advances in antimicrobial eatable layers for food may hold guarantee in broadening timeframe of realistic usability, decreasing bundling layers, meeting sanitation and quality prerequisites. Rising examination shows bacteriocins, polysaccharides, chemicals, fundamental oils, lipids and proteins are on the whole common coatings that have hidden potential in food safeguarding. As of late, intrigue has expanded in utilizing Aloe vera gel-based eatable covering material for leafy foods. Aloe vera gel has been demonstrated extraordinary compared to other eatable and naturally safe additive coatings for various sorts of nourishments as a result regards to its film-shaping properties, biodegradability, antimicrobial activities as well as biochemical properties. Its made predominantly out of polysaccharides and goes about as a characteristic boundary to dampness and oxygen, which are the principle operators of crumbling of products of the soil. Aloe vera gel can draw out time span of usability of the leafy foods by limiting the pace of breath and keeping up quality characteristics (shading, flavor and so forth). It has antifungal as well as antibacterial property, it gives a guarded obstruction against microbial defilement of leafy foods. The current survey portrays the readiness, properties and potential utilization with regards to Aloe vera gel coatings for upgrading postharvest life as well as nature of various sorts regards to organic products. (Misir et al. 2014).
\end{abstract}

The term Aloe is obtained from the name Arabic "Alloeh" or the Hebrew "Halal" connoting "unsavory, shinny substance"(Gage D, 1996). Aloe vera is even called same as "plant of never-ending status" by the Egyptians in light regards to its significant outcome on prosperity of human. It is all around accepted that the source is Sudan, Arabia, Somalia, and Oman. At present, Aloe vera is commonly passed on all through the subtropics and tropics (Schmelzer, 2008). Aloe vera is an enduring plant. It's densed, thorn edged leaves, stretching out in concealing from diminish to splendid green, give Aloe vera the nearness of a thorny plant. An ordinary Aloe vera plant delivers a couple of yellow tube shaped blooms, framed a great deal of like those of the Easter Lily, and it blooms sporadically reliably (Gage D, 1996). In the current society various people do have food hypersensitivities or individual tendencies that will shield them through ingesting these things. Henceforth, Aloe vera is an unfathomable dietary source used to fulfill the needs of amino acids (Misir et al. 2014).

\section{Effect of coatings on attributes of guava (Psidium guajava)}

A preliminary was coordinated to think about the reaction of gum Arabic layers on physicochemical and material attributes of guava (Psidium guajava L cv. Shweta) during limit at encompassing conditions for nine days. The physical and also the biochemical recognitions both were put down at three days stretch in the course of amassing. The gum arabic 10\% covering basically diminished physiological hardship inside the weight (PLW) and held higher steadfastness, ascorbic destructive, strip chlorophyll content and appealing common items when diverged from control. The base PLW and the most outrageous ascorbic destructive, strip chlorophyll and faithfulness were found in GA 10\% secured regular items, while uncoated natural items offered an explanation to having higher PLW (19.23\%) and lower ascorbic destructive, strip chlorophyll and endurance close to the completion of the 9 days accumulating period. Most outrageous value regarding concealing (7.66) held by gum arabic (10\%) followed by 5\% GA (7.48) covering at the finish of the limit. The already stated suggest that usage of GA $10 \%$ covering was practical for holding physicoengineered attributes of guava as well as the defending of the substantial characteristics of the normal item during limit at ambient room temperature. (Gurjar et al. 2018).

In a study the fundamental oils have been assessed as defensive eatable coatings. The organic products Guava (Psidium guajava) and Amla (Amblica officinalis) were covered by dunking in fundamental oils of Tulsi, Neem and Eucalyptus and pressed in CFB, Brown paper and LDPE. The natural products were put away at room temperature and loss of weight (\%), debris content (\%), dampness content (\%), TSS $\left({ }^{\circ} \mathrm{B}\right)$, Ascorbic corrosive substance (mg/ml), absolute plate check (CFU/ml) and absolute yeast and form tally were surveyed. The coatings brought about a decrease of weight reduction, dampness content and Ascorbic corrosive substance. Guava and Amla covered with Neem oil and Packed in LDPE demonstrated decrease in microbial checks, TSS and Ash content contrasted and the control. The productivity was better than that of Tulsi and Eucalyptus treatment which were stuffed in CFB and earthy colored paper. This examination proposes that by utilizing Neem oil as a palatable covering stuffed in LDPE, the rotting of Guava and Amla can be deferred and can be protected for as long as 12 days during capacity at room temperature with no negative impacts on postharvest quality. (Sebastian et al. 2018).

The end result of layers with various centralizations with regards to tamarind seeds starch related along with oil of pomegranate seeds in 'Paluma' guava was explored inside the work. The regular items were procured through an estate inside the first part of the day, squeezed in compartments as of late fixed along with paper and sent to a 
lab, at that place they were picked, washed, sanitized and secluded aimlessly for the utilization of every treatment. The examination design which was used, completely randomize in the $6 \times 6$ factorial arrangement, six layers as well as six appraisal periods, along with 3 copies involved 2 natural items. The drugs were applied under immersion of the characteristic items in the courses of action and a short time later set aside inside a chamber of refrigerated at $10 \pm 2{ }^{\circ} \mathrm{C}$ with $80 \pm 5 \% \mathrm{RH}$ and the appraisals were experimented at time spans days to 12 extensive stretches of limit. In view of the upkeep of the idea of the natural items and without satisfactory material it was picked to expand limit time until the 21 days. Thusly, the assessments were experimented at $0,3,6,9,12$ and 21 days with evaluations at $0,3,6,9,12$ as well as 21 days. The treatment (3\% tamarind starch $+0.24 \mathrm{~mL} / \mathrm{mL}$ pomegranate seed oil) was more beneficial regarding sparkle ( $\left.\mathrm{L}^{*}\right)$ of the nourishments developed from the beginning improvement conveyed by the assessments, similarly demonstrating the higher support in the loss of robustness lower mass adversity as well as lower dissolvable solids content, suggesting that this treatment possibly controlled the debasement of polysaccharides conceding the maturing pattern of the normal items. (Onias et al. 2018).

An impact on added substances into Aloe vera gel covering was examined on new slice guava put away at $5^{\circ} \mathrm{C}$ and 74-80\% relative mugginess. Eight medicines were utilized including three added substances and their blends. The covered examples had less difference in the shading delicacy and yellowness contrasted with the uncoated example. Five chose covered tests and a new uncoated example were then exposed to tangible acknowledgment testing. AV + AA + PS-covered guava was the most satisfactory example. In addition, it gave the most elevated ascorbic corrosive substance $(190.00 \pm 14.14 \mathrm{mg}$ per 100 g). With appropriate added substances, AV gel has potential as a consumable covering for new slice guava because of its capacity to drag out the time span of usability and keep up qualities of the natural product for a longer time (Nasution et al. 2015).

A research showed that the primary point of the examination was to evaluate the viability of various consumable covering medicines like chitosan, calcium chloride, sodium alginate and Aloe vera gel at different fixations on the post-collect quality traits of products of guava cultivar 'Gasp Prabhat'. After treatment, natural products were stored at surrounding condition of $27-29^{\circ} \mathrm{C}$ upto 12 days and broke down for different practical and tactile boundaries while the uncoated natural products fill in as control. Consequently, it was reasoned that covering treatment of $1.5 \%$ chitosan followed by Aloe vera 1:1 gel covering can be utilized for improving the timeframe of realistic usability and keeping up postharvest quality in products of guava cultivar 'Gasp Prabhat' (Kumar et al. 2017).

\section{Summary}

Consumable coatings are used from various years for limit of Fruits and Vegetables in food industry. Diverse covering substances are utilized for covering, for example, waxes, hydrocolloids, protein. Researchers have made new acceptable coatings, it is ensured and condition welcoming and safely eaten with Fruits and Vegetables. As per this survey, edible coatings expands timeframe of realistic usability, lessen water and dampness misfortune, postponed maturing measure and furthermore forestall microbial development explicitly in new foods grown from the ground. In eatable covering, as of late another idea has been presented and it is home grown eatable covering. It gives better outcomes and medical advantages. Natural palatable covered Fruits and Vegetables contained supplements and go about as medications.

\section{REFERENCES}

1. Abraham, J., \& Banerjee, A. Study on the Efficacy of Aloe Vera Gel Blended With Xanthan Gum Gel In Enhancing the Shelf Life of Guava.

2. Adentuji C.O., Arowora K.A., Fawole O.B., Nwaubani S.I., Ajayi E.S., et.al; "Effects of Edible Coatings from Aloe Vera Gel on Quality and Postharvest Physiology of Ananas comosus (L.) Fruit during Ambient Storage”; Global Journal of Science Frontier Research; 12(5); 2012; 38-43.

3. Aniseh, Bahareh Shabanpour; "Quality Characteristics of Fried Rainbow Trout (Oncorhynchus mykiss) Fillets Coated with Different Hydrocolloids Edible Films”; World Journal of Fish and Marine Sciences; 5(4); 2013; 398-404.

4. Asrar Y.I., et al; "Utilization of edible coating in extending the shelf life of minimally processed prickly pear”; Journal of Applied Sciences Research, 9(2); 2013; 1202-1208.

5. Gage, D. (1996). Aloe vera: Nature's soothing healer. Inner Traditions/Bear \& Co.

6. Gurjar, P. S., Killadi, B., Lenka, J., \& Shukla, D. K. (2018). Effect of Gum Arabic Coatings on PhysicoChemical and Sensory Qualities of Guava (Psidium guajava L) cv. Shweta. International Journal of Current Microbiology and Applied Sciences, 7, 37693775.

7. Hailu, G., \& Derbew, B. (2015). Extent, causes and reduction strategies of postharvest losses of fresh 
fruits and vegetables-A review. Journal of Biology, Agriculture and Healthcare, 5(5), 49-64.

8. Jawadul, Brishti Fatema H., Hoque M. M.; "Aloevera Gel as a Novel Edible Coating for Fresh Fruits: A Review”; American Journal of Food Science and Technology; 2(3); 2014; 93-97.

9. Kader, A.A. 2002. Quality parameters of fresh-cut fruit and vegetable products, pp. 11-28. In O. Lamikanra, (ed.). Fresh-Cut Fruits and Vegetables: Science, Technology and Market. CRC Press. Boca Raton, FL, USA.

10. Krishna K., D.V. Sudhakar Rao; "Effect of Chitosan Coating on the Physiochemical characteristics of Guava (Psidium guajava L.) Fruits during Storage at Room Temperature"; Indian Journal of Science and Technology; 7(5); 2014; 554-558.

11. Kumar A, Singh O, Kohli K and Dubey C M (2017) Effect of edible surfacecoating on post-harvest quality and shelf life of Guava (Psidium guajava L.) Cv. Pant Prabhat. Thebioscan 12(2): 825-832.

12. Misir, J., Brishti, F. H., \& Hoque, M. M. (2014). Aloe vera gel as a novel edible coating for fresh fruits: A review. American Journal of Food Science and Technology, 2(3), 93-97.

13. Nasution, Z., Ye, J. N. W., \& Hamzah, Y. (2015). Characteristics of fresh-cut guava coated with Aloe vera gel as affected by different additives. Agriculture and Natural Resources, 49(1), 111-121.
14. Oms-Oliu, G., M.A. Rojas-Grau, L.A. Gonzalez,P. Varela, R. Soliva-Fortuny, M.I.H. Hernando,I.P. Munuera, S. Fiszman and O. Martin-Belloso. 2010. Recent approaches using chemical treatments to preserve quality of fresh-cut fruit: A review. Postharvest Biol. Tec. 57: 139-148.

15. Raghav, P. K., Agarwal, N., \& Saini, M. (2016). Edible coating of fruits and vegetables: a review. International journal of scientific research and modern education, 1(1), 188-204.

16. Rojas-Grau, M.A., G. Oms-Oliu, R. SolivaFortuny and O. Martin-Belloso. 2009a. The use of packaging techniques to maintain freshness in freshcut fruits and vegetables: A review. Int. J. Food Sci. Tech. 44: 875-889.

17. Schmelzer, G.H., Medicinal Plants, PROTA, Backhuys Publishers, Wageningen, 2008, 82.

18. Tomar RS, Ranjit Pal, Prabha Singh, Sushma Tiwari, Mohd Tasleem, Ashutosh Singh, Pratibha Pandey and AK Pandey (2020). Jamun an underexploited indigenous fruit tree of india: a Review, International Journal on Agricultural Sciences, 11 (1):38-42

19. Watada, A.E. and L. Qi. 1999. Quality of fresh-cut produce. Postharvest Biol. Tec. 15: 201-205.

20. Wijewardane R.M.N.A.; "Application of Polysaccharide Based composite Film Wax Coating For Shelf-life Extension Of Guava ( var. Bangkok Giant)”; Journal of Postharvest. 